\title{
CORRECTION
}

\section{Correction to: Ascitic Calprotectin as an early predictor of hepatocellular carcinoma in patients with cirrhotic ascites}

\author{
Amr Shaaban Hanafy ${ }^{1}$ (D) $\cdot$ Mohamed Sorour Mohamed ${ }^{1} \cdot$ Ahmed A. Alnagar $^{2}$
}

Published online: 18 November 2021

○) Springer-Verlag GmbH Germany, part of Springer Nature 2021

\section{Correction to:}

Journal of Cancer Research and Clinical Oncology

The original article has been corrected.

\section{(2020) 146:3207-3214}

https://doi.org/10.1007/s00432-020-03363-y

In the original article published, the figures 3 and 4 are published incorrectly. The correct Figs. 3 and 4 are as given below.

The original article can be found online at https://doi.org/10.1007/ s00432-020-03363-y.

Amr Shaaban Hanafy

Dr_amr_hanafy@yahoo.com

1 Internal Medicine Department, Hepatogastroenterology

Division, Zagazig University, 40 Mostafa Fouad street

44519, Zagazig, Egypt

2 Medical Oncology, Zagazig University, Zagazig, Egypt 


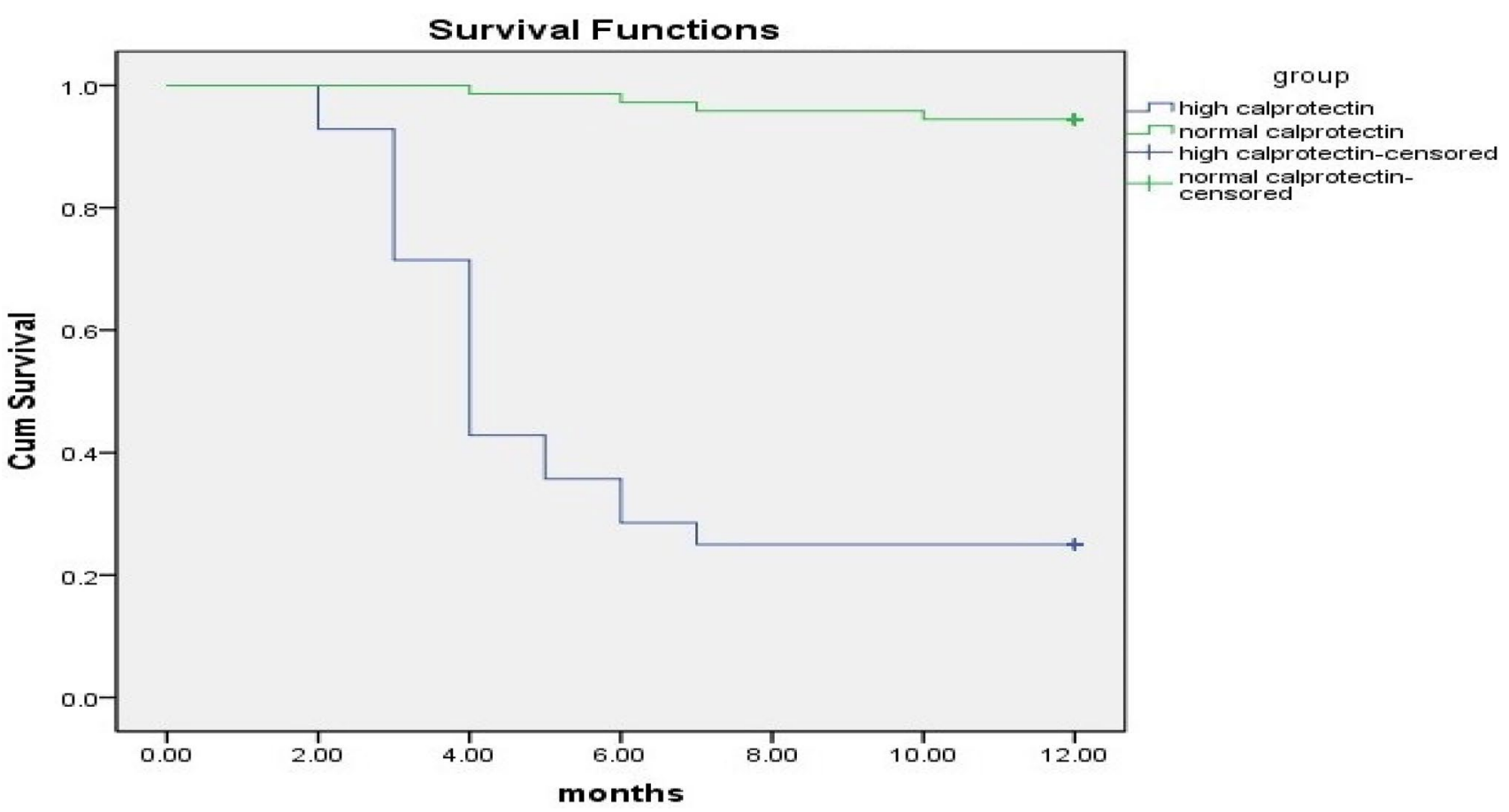

Fig. 3 Time of occurrence of HCC in a group with elevated ascetic Calprotectin compared to a group with normal value

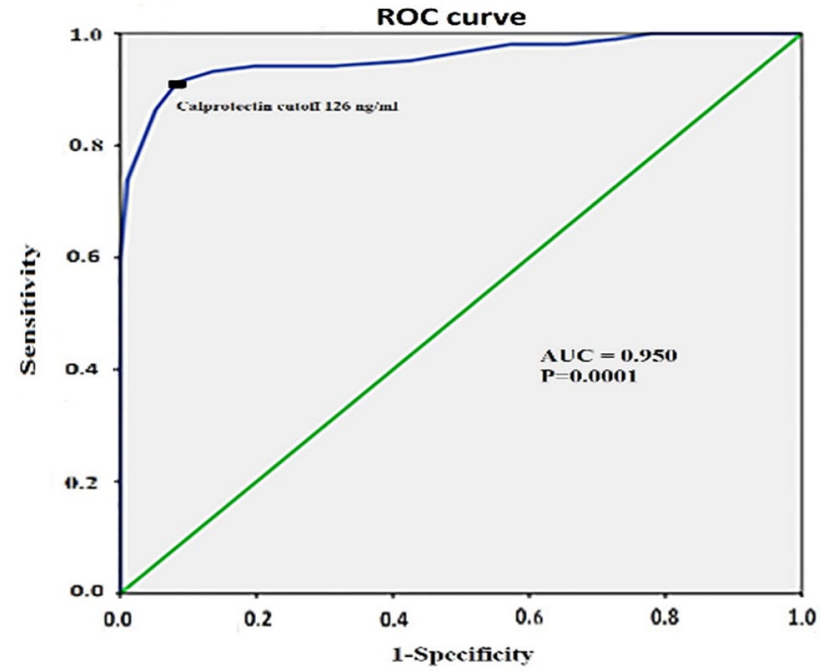

Fig. 4 Receiver operating characteristics analysis of the ascitic Calprotectin to identify risk of occurrence of HCC

Publisher's Note Springer Nature remains neutral with regard to jurisdictional claims in published maps and institutional affiliations. 